\title{
Loa-Kea Hawai'i Geochemical Trends: Recent Findings and Future Directions
}

\author{
DOMINIQUe Weis ${ }^{1}$, NiCOLE M.B. WILLIAMSON ${ }^{1}$, \\ LAUREN N. HARRISON ${ }^{1,2}$, LAURA D. BILENKER ${ }^{3}$ \\ ${ }^{1}$ Pacific Centre for Isotopic and Geochemical Research, \\ Earth, Ocean \& Atmospheric Sciences, Univ. of British \\ Columbia, Vancouver, BC V6T1Z4, Canada, \\ dweis@eoas.ubc.ca, nwilliam@eoas.ubc.ca \\ ${ }^{2}$ Lawrence Livermore National Lab, Livermore, CA 94551, \\ USA, harrison56@1lnl.gov \\ ${ }^{3}$ Auburn University, Department of Geosciences, Auburn, AL \\ 36849, USA,_LDB0036@auburn.edu
}

Hawaiian volcanoes belong to two geographically and geochemically distinct trends, Loa and Kea ${ }^{1,2}$, whose origin is strongly debated. One of the prevailing hypotheses is that the two trends originate in the deep mantle where the Hawaiian plume straddles two geophysically distinct domains at the core-mantle boundary (CMB). The $\mathrm{Pb}, \mathrm{Hf}, \mathrm{Nd}$, and $\mathrm{Sr}$ isotopic compositions of shield lavas from certain volcanoes (Lō'ihi, Kohala, Haleakalā) are transitional, calling into question the degree of independence between the two trends. Kaua'i, the oldest island ( $\sim 5 \mathrm{Ma})$, shows a rotated distribution of Loa and Kea compositions and Northwest Hawaiian Ridge volcanoes (47-6 Ma) do not record a bilateral Loa-Kea trend at the current sampling resolution ${ }^{3,4}$. Statistical analysis of $\mathrm{Pb}$ isotope data from shield stage tholeiitic basalts ( $>800$ samples) for the Hawaiian Islands $(<6.5 \mathrm{Ma})$ resolves six unique geochemical groups and documents large-scale heterogeneities in the Kea trend for the first time. The spatial orientation of these groups shows that the bilateral zonation of the Hawaiian mantle plume at the $\mathrm{CMB}$ is gradational and that the Hawaiian plume periodically entrains large-scale geochemical heterogeneities that grade into, and out of, existence on million-year, regional timescales $^{4}$. We are investigating $\mathrm{Tl}$ and $\mathrm{Fe}$ isotopic variations in a subset of shield lavas to help charaterize the processes and sources of these previously unrecognized heterogeneities within each of the regional bilateral Loa and Kea trends. The regional-scale geochemical compositions along the Hawaiian Islands support the presence of chemical heterogeneities of variable size and life-span within both the large, thermochemical low shear wave velocity province (LLSVP) at the CMB and in the ambient deep Pacific mantle.

[1] Weis et al. (2011) Nat. Geo. 4, 831-838. [2] Abouchami et al. (2005) Nat. 434, 851-856. [3] Williamson et al. (2019) Geochem. Geophys. Geosys. 20, 10.1029/2019GC008451 [4] Harrison et al. (2018) Geochem. Geophys. Geosys. 19(8), 10.1029/2017GC007389. 